\title{
Treatment of Pleural Effusion after Lobectomy and Lymphadenectomy for Primary Lung Cancer: A Case Report
}

\author{
Alexei L. Charyshkin, PhD, ScD ${ }^{1 *}$; Ekaterina A. Kuzmina ${ }^{2}$; Evgeniy A.Toneev ${ }^{1,3}$; \\ Bulat I. Khusnutdinov ${ }^{1,3}$; Aleksander A. Martynov ${ }^{3}$; Vladimir I. Midlenko, PhD, ScD ${ }^{1}$ \\ ${ }^{1}$ Ulyanovsk state University, Ulyanovsk, Russia \\ ${ }^{2}$ Pirogov Russian National Research Medical University, Moscow, Russia \\ ${ }^{3}$ Regional Clinical Oncology Center, Ulyanovsk, Russia
}

\begin{abstract}
The majority of malignant pleural effusion (MPE) is caused by metastatic disease: most commonly lung cancer in men and breast cancer in women. MPE worsens the quality of life in patients due to the occurrence of respiratory failure, compression of internal organs and violation of homeostasis. Existing methods for MPE treatment have a number of disadvantages, including insufficient analgesia and the use of standard drainage tubes that do not adequately irrigate the pleural space with drugs, thereby reducing the drugs' effectiveness. The proposed method for the treatment of MPE improves the treatment results by improving the drainage and introduction of drugs into the pleural cavity. (International Journal of Biomedicine. 2020;10(1):76-78.)
\end{abstract}

Key Words: malignant pleural effusions $\bullet$ thoracentesis $\bullet$ pleurodesis

\section{Introduction}

Worldwide, the incidence of cancer and malignant pleural effusion (MPE) is increasing annually. There are more than 100,000 new cases of MPE yearly in Russia. ${ }^{(1-3)}$

MPE worsens the quality of life in patients due to the occurrence of respiratory failure, compression of internal organs and violation of homeostasis. Repeated thoracentesis has the potential risks of inducing hypoproteinemia, empyema and pneumothorax. Without adequate therapy, all these circumstances lead to decompensation of the main body systems and death in a short period of several months. ${ }^{(3,4)}$ More than $800 \mathrm{ml}$ of pleural effusion leads to respiratory failure, lung atelectasis that causes hypercapnia and hypoxemia. ${ }^{(3-5)}$

Existing methods for MPE treatment have a number of disadvantages, including insufficient analgesia and the use of standard drainage tubes that do not adequately irrigate the pleural space with drugs, thereby reducing the drugs' effectiveness. ${ }^{(4-6)}$ As a result, palliative treatments are needed

*Corresponding author: Prof. Alexei L. Charyshkin, PhD, $S c D$. Head of the Faculty Surgery Department, Institute of Medicine, Ecology and Physical Education, Ulyanovsk State University. Ulyanovsk, Russia.E-mail: charyshkin@yandex.ru to effectively control pleural effusions and relieve symptoms.

The aim of our study was to improve the results of treatment of patients with MPE by improving the drainage and introduction of drugs into the pleural cavity.

"A method for the treatment of exudative pleurisy" was developed in the Department of Faculty Surgery at Ulyanovsk State University (Application for invention No. 2019103176; Priority of 02/02/2019) (Authors: Charyshkin AL, Toneev EA, Martynov AA, Khusnutdinov BI).

The proposed method is performed as follows: Thoracentesis is performed in the posterior axillary line $(6 \mathrm{~cm}-10 \mathrm{~cm}$ lateral to spine) at the level of the eighth intercostal space using a silicone tube with a diameter of 5 $\mathrm{mm}$. A chest X-ray is performed one day after the pleural cavity drainage. If the pleural cavity is dry and the lung is fully inflated, the silicone tube is removed and replaced by a polyurethane catheter (a diameter of $2 \mathrm{~mm}$ ). The inner part of the catheter, located in the pleural cavity, has 8 through holes with a diameter of $1 \mathrm{~mm}$. As premedication, Tramal is intramuscularly administered, and $50 \mathrm{ml}$ of Naropin (100 $\mathrm{mg}$ ) and physiological saline $50 \mathrm{ml}$ are injected through the catheter. The external end of the catheter is pinched and the patient lies in different positions for 30 minutes. Next, the clamp is removed and $30 \mathrm{ml}$ of $10 \%$ Betadine solution and 60 
$\mathrm{ml}$ of Naropine $(120 \mathrm{mg})$ are introduced through the catheter. The external end of the catheter is squeezed for 8 hours. During this time the patient is lying down, and every 2 hours changes the position of the body; then the clamp is removed and active aspiration is performed within 12 hours. Finally, the catheter is removed.

We believe that applying the developed method prevents purulent-inflammatory complications, which often develop with prolonged drainage of the pleural cavity. ${ }^{(3,7-9)}$ The described technique is used in the Ulyanovsk Regional Oncology Clinical Dispensary and has been performed on 23 patients with a positive result.

\section{Case presentation}

A 54-year-old white male was admitted to the surgical thoracic department of the Regional Oncology Clinical Center of Ulyanovsk for surgical treatment with a diagnosis of a lung cancer of the right upper lobe. The planned operation: Right thoracotomy, upper lobectomy, and systemic lymph node dissection.

On Day 6 after surgery, the postoperative period was complicated by exudative pleurisy. We drained the pleural cavity according to the developed methods, and $400 \mathrm{ml}$ of exudates was removed. A day after the pleural cavity was drained, an X-ray control was performed, which showed the dry pleural cavity and fully inflated lung. Subsequent stages of the intervention were performed in accordance with the method described above. After the active aspiration was completed, repeated X-ray examination showed the presence of a dry pleural cavity and fully inflated lung; the catheter was removed. Pain intensity according to the Visual Analogue Scale scored 2 points. The postoperative period was uneventful; wound healing passed by primary intention. The patient was discharged from the hospital in satisfactory condition under the supervision of an oncologist at his place of residence. The patient was examined after one year; no recurrence of the disease was detected.

The majority of MPE is caused by metastatic disease: most commonly lung cancer in men and breast cancer in women. ${ }^{(3,10-13)}$ The presence of MPE indicates an advanced stage of the disease with a median life expectancy of 3 to 12 months, depending on the stage and type of underlying malignancy. ${ }^{(14)}$ During the past two decades, there has been a change in direction in MPE research and management. Advanced, minimally invasive methods are becoming increasingly important. ${ }^{(3,15,16)}$ Instead of aggressive surgical methods, the current treatment approach for patients with MPE is mainly aimed at alleviating symptoms and improving quality of life indicators, which is a key goal of treatment. ${ }^{(17)}$

Among treatment methods, two effective treatments recommended for recurrent MPE are pleurodesis and IPC placement, both of which can effectively improve dyspnea and quality of life of patients. ${ }^{(11,17-21)}$ However, these treatments are also temporary, and MPE would recur soon. The proposed method for the treatment of MPE contributes to a pronounced analgesic effect, and reduces treatment time and recurrence of the disease. The described clinical case confirms the method's effectiveness.

\section{Competing Interests} interests.

The authors declare that they have no competing

\section{References}

1. Merabishvili VM, Arseniev AI, Tarkov SA, Barchuk AA, Shcherbakov AM, Demin EV, Merabishvili EN. [Lung cancer morbidity and mortality]. Siberian Journal of Oncology 2018; 17 (6):15-26. [Article in Russian].

2. Klimenko VN, Ivanov OV. [Tumor pleurisy: a modern view of the problem]. Grekov's Bulletin of Surgery. 2014;173(2):114-117. [Article in Russian].

3. Klimenko V.N., Ivanov OV. [Diagnosis and tactics of treatment of tumor pleurisy on an outpatient basis]. Voprosy Onkologii. 2015;61(6):949-955. [Article in Russian].

4. Psallidas I, Kalomenidis I, Porcel JM, Robinson BW, Stathopoulos GT. Malignant pleural effusion: from bench to bedside. Eur Respir Rev. 2016;25(140):189-98. doi: 10.1183/16000617.0019-2016.

5. Perricone G, Mazzarelli C. Images in clinical medicine. Reexpansion pulmonary edema after thoracentesis. N Engl J Med. 2014;370(12):e19. doi: 10.1056/NEJMicm1309844.

6. Thomas R, Francis R, Davies HE, Lee YC. Interventional therapies for malignant pleural effusions: the present and the future. Respirology. 2014;19(6):809-22. doi: 10.1111/ resp. 12328.

7. Agarwal R, Khan A, Aggarwal AN, Gupta D. Efficacy \& safety of iodopovidone pleurodesis: a systematic review \& meta-analysis. Indian J Med Res. 2012;135:297-304.

8. Plaksin SA, Farshatova LI. A method for the treatment of exudative pleurisy. Patent for Invention RUS No. 2666401. Application No. 2017122884 dated 06/28/2017. Publ. 09/07/2018; bulletin No. 25. [In Russian].

9. Charyshkin AL, Toneev EA. Results of surgical treatment of lung cancer in patients of different age groups. International Journal of Biomedicine. 2017;7(2):144-146. doi: 10.21103/ article7(2)_shc1

10. Chuchalin AG. Pulmonology: national manual. Brief Edition. M., «Geotar Media»; 2013. [In Russian].

11. Xia H, Wang XJ, Zhou Q, Shi HZ, Tong ZH. Efficacy and safety of talc pleurodesis for malignant pleural effusion: a meta-analysis. PLoS One. 2014;9(1):e87060. doi: 10.1371/ journal.pone.0087060.

12. Zhestkov KG, Iaduta RT. [The role and place of talc in malignant pleuritis management (literature review)]. Pirogov Russian Journal of Surgery. 2016;(1):40-44. [Article in Russian].

13. Clive AO, Bhatnagar R, Psallidas I, Maskell NA. Individualised management of malignant pleural effusion. Lancet Respir Med. 2015;3(7):505-6. doi: 10.1016/S22132600(15)00183-6.

14. Kasapoglu US, Arınç S, Gungor S, Irmak I, Guney P, Aksoy F, et al. Prognostic factors affecting survival in nonsmall cell lung carcinoma patients with malignant pleural effusions. Clin Respir J. 2016;10(6):791-799. doi: 10.1111/ crj.12292.

15. Thomas R, Fysh ETH, Smith NA, Lee P, Kwan BCH, Yap E, et al. Effect of an Indwelling Pleural Catheter vs Talc Pleurodesis on Hospitalization Days in Patients With Malignant Pleural Effusion: The AMPLE Randomized 
Clinical Trial.JAMA. 2017;318(19):1903-1912. doi: 10.1001/ jama.2017.17426.

16. Shulutko AM, Ovchinnikov AA, Yasnogorodsky OO, Motus IYa. Endoscopic Thoracic Surgery: A Guide for Physicians. M.: Meditsina; 2006. [In Russian].

17. Davies HE, Mishra EK, Kahan BC, Wrightson JM, Stanton AE, Guhan A, et al. Effect of an indwelling pleural catheter vs chest tube and talc pleurodesis for relieving dyspnea in patients with malignant pleural effusion: the TIME2 randomized controlled trial. JAMA. 2012;307(22):2383-9. doi: 10.1001/ jama.2012.5535.

18. Charyshkin AL, Toneev EA, Martynov AA, Lisyutin RI, Zul'karnyaev ASh. Synchronous multiple primary lung cancer: a case report. International Journal of
Biomedicine.2018;8(2):162-164 doi: 10.21103/Article8(2) CR1 19. Charyshkin AL, Toneev EA, Medvedev AA. [The results of the use of lymphotropic therapy in patients with lung cancer]. Voprpsy Onkologii. 2019;65(1):106-109. [Article in Russian].

20. Maskell NA, Lee YC, Gleeson FV, Hedley EL, Pengelly $\mathrm{G}$, Davies RJ. Randomized trials describing lung inflammation after pleurodesis with talc of varying particle size. Am J Respir Crit Care Med. 2004;170(4):377-82.

21. Fysh ETH, Tremblay A, Feller-Kopman D, Mishra EK, Slade M, Garske L, et al. Clinical outcomes of indwelling pleural catheter-related pleural infections: an international multicenter study. Chest. 2013;144(5):1597-1602. doi: 10.1378/chest.12-3103. 